\title{
X-Ray Crystal Structures of Short Antimicrobial Peptides as Pseudomonas aeruginosa Lectin B Complexes
}

Stéphane Baeriswyl, Bee-Ha Gan, Thissa N. Siriwardena, Ricardo Visini, Maurane Robadey, Sacha Javor, Achim Stocker, Tamis Darbre and Jean-Louis Reymond*

a) Department of Chemistry and Biochemistry, University of Bern, Freiestrasse 3, 3012 Bern, Switzerland.

\section{Abstract}

Herein we report X-ray crystal structures of 11-13 residue antimicrobial peptides (AMPs) active against Pseudomonas aeruginosa as complexes of fucosylated D-enantiomeric sequences with the $P$. aeruginosa lectin LecB. These represent the first crystal structures of short AMPs. In twenty-four individual structures of eight different peptides we found mostly $\alpha$-helices assembled as two-helix or four-helix bundles with a hydrophobic core and cationic residues pointing outside. Two of the analogs formed an extended structure engaging in multiple contacts with the lectin. Molecular dynamics (MD) simulations showed that $\alpha-$ helices are stabilized by bundle formation and suggested that the N-terminal acyl group present in the linker to the fucosyl group can extend the helix by one additional H- bond and increase $\alpha$-helix amphiphilicity. Investigating N-terminal acylation led to AMPs with equivalent and partly stronger antibacterial effects compared to the free peptide. 


\section{Introduction}

The emergence of multidrug resistant (MDR) Gram-negative bacteria such as Pseudomonas aeruginosa and Acinetobacter baumannii in the hospital environment is calling for the development of new antibacterial agents. ${ }^{(1-3)}$ Antimicrobial peptides (AMPs), which occur in microorganisms, plants and animals as components of innate immunity, offer a promising opportunity to address this challenge. ${ }^{(4-6)}$ Many of these AMPs are short peptides which fold into amphiphilic $\alpha$-helices in contact with the bacterial membrane,(7-14) leading to aggregation inducing membrane disruption, morphological changes and cell lysis as documented by imaging studies.(15-18) Such short AMPs can exert potent effect against multidrug resistant bacteria and their biofilms, $(19,20)$ and show potent activities in vivo.(21) Interestingly, the experimental evidence for $\alpha$-helix formation in these peptides is mostly based on circular dichroism (CD) and NMR studies.(22) Direct crystallographic evidence for $\alpha$-helices in short AMPs(23) has only been reported for mastoparan MP-PJ (14 residues),(24) mellitin (26 residues), toxic to both prokaryotic and eukaryotic cells,(25) and an analog of magainin II (23 residues) with a crystal structure of the racemic form,(26) as well as for peptaibols, a special class of non-ribosomal peptides forming ion channels and which fold into an unusual 310-helix induced by amino-isobutyric acid residues.(27-29)

Herein we report X-ray crystal structures of analogs of the 13 residue peptide KYKKALKKLAKLL (SB1), initially reported by Hancock and coworkers to be active against $P$. aeruginosa,(30) in form of complexes of fucosylated D-enantiomeric sequences (e.g. SB4, Scheme 1) with P. aeruginosa lectin LecB.(31) These are the first X-ray crystal structures of short $\alpha$-helical AMPs targeting Gram-negative bacteria. This report builds on our previous examples of using LecB complexes to access structural data for molecules otherwise 
difficult to crystallize such as oligonucleotides,(32) glycopeptide dendrimer biofilm inhibitors,(33-39) cyclic and bicyclic AMPs.(40, 41)

The fucosylated peptides reported here act similarly to SB1 by folding into amphiphilic and membrane disruptive helices. The crystal structures of their LecB complexes show that they mostly form $\alpha$-helices assembled via hydrophobic contacts into two-helix or four-helix bundles, although two sequences present an unfolded extended structure in their LecB complexes. Molecular dynamics (MD) simulations show that $\alpha$-helices are stabilized by bundle formation in the crystal but are not stable in pure water as single entities. They also suggest that the $\mathrm{N}$-terminal acyl group added as a linker to the fucosyl group can extend the helix by one additional H-bond and thereby increase $\alpha$-helix amphiphilicity. Investigating $\mathrm{N}$ terminal acylation led to AMP analogs displaying equivalent and partly stronger antibacterial effects against different Gram-negative strains as well as P. aeruginosa biofilm inhibition compared to the free peptide.

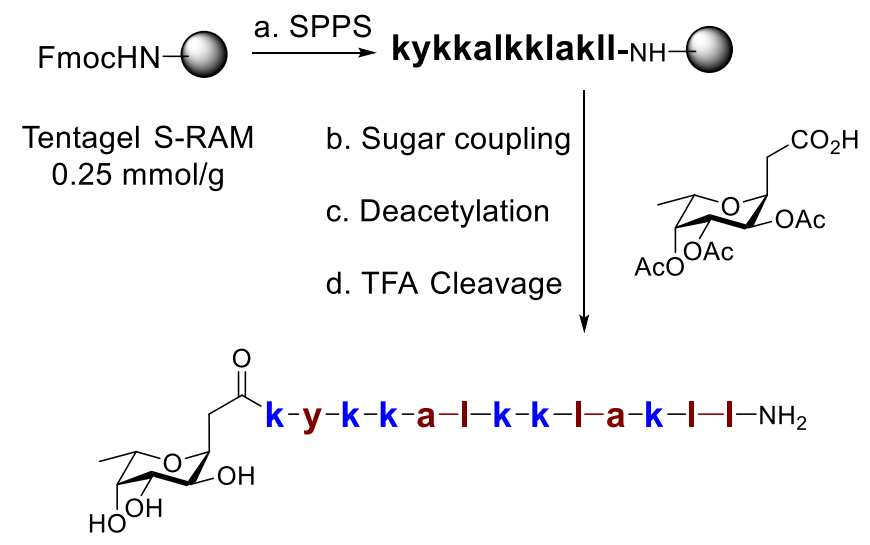

Scheme 1. Synthesis of AMP SB4. Conditions: a. (i) Piperidine/DMF (1/4; v/v), RT, $2 x 20 \mathrm{~min}$, (ii) FmocAAOH, oxyma/DIC (3 eq), NMP/DCM (6/1, v/v); RT, 1.5 h. b. Peracetylated $\alpha$-L-fucosyl-acetic acid, oxyma/DIC (5 eq), NMP/DCM (6/1, v/v), RT, overnight. c. $\mathrm{MeOH} / \mathrm{H}_{2} \mathrm{O} / 25 \% \mathrm{NH}_{4} \mathrm{OH}(8: 1: 1, \mathrm{v} / \mathrm{v} / \mathrm{v}), 12 \mathrm{~h}$. d. TFA/TIS/ $\mathrm{H}_{2} \mathrm{O}(94: 5: 1, \mathrm{v} / \mathrm{v} / \mathrm{v}), 3 \mathrm{~h}$. 


\section{Results and Discussion}

\section{Synthesis of SB1 and analogs}

Aiming to perform functional and structural studies we prepared the 13-mer AMP SB1 and its D-enantiomer SB2 as well as the corresponding $N$-terminally C-fucosylated derivatives SB3 and SB4 by N-terminal acylation using peracetylated $\alpha$-C-fucosylacetic acid as described previously for peptide dendrimers (Scheme 1).(42) We also prepared shorter fucosylated analogs focusing on D-enantiomeric sequences because fucosylated L-sequences only generated few diffracting crystals where the peptides were not resolved. Specifically, we removed one or two residues at each end of the peptide to test the dependence of folding on sequence length (SB5-SB9). Furthermore, we synthesized the retro-inverso sequence (SB10) and its shortened analogs (SB11-SB15) to investigate folding in a modified context. Following our structural studies, we finally prepared N-terminally acylated analogs SB16SB18 to test the influence of this modification on folding and activity (Table 1).

\section{SB1 is a typical membrane disruptive AMP}

The 13-residue AMP SB1 is predicted to fold into an amphiphilic $\alpha$-helix clustering cationic and hydrophobic side chains on opposite sides of the helix (Figure 1a). Analysis of CD spectra using Dichroweb(43) showed a transition from a disordered conformation in water to an $\alpha$-helical conformation upon addition of up to $20 \% \mathrm{v} / \mathrm{v}$ trifluoroethanol (TFE), which partly mimics the reduced polarity environment of the bacterial membrane. This behavior is typical of short amphiphilic and membrane disruptive AMPs (Figure 1b).(5, 44) As expected from this folding behavior, SB1 exhibited membrane disruptive activity in vesicle leakage experiments with vesicles consisting of phosphatidyl glycerol (PG) mimicking the bacterial 
membrane (Figure 1c). Vesicles consisting of phosphatidyl choline (PC) similar to the

membrane of eukaryotic cells were also affected (Figure 1d), although SB1 showed negligible

hemolysis (Table 1). The D-enantiomeric sequence SB2 showed similar folding and

membrane disruptive properties.

Table 1. Sequences, $\alpha$-helical content and activity of SB1 and C-fucosylated analogs on P. aeruginosa.

\begin{tabular}{|c|c|c|c|c|c|c|c|c|}
\hline \multirow[t]{2}{*}{ Cpd. } & \multirow[t]{2}{*}{ Sequence $^{a)}$} & \multirow[t]{2}{*}{$\mathbf{N}^{\mathbf{b})}$} & \multicolumn{2}{|c|}{$\% \alpha$-helix ${ }^{c)}$} & \multicolumn{2}{|c|}{ Vesicle leakage $(\%)^{\text {d) }}$} & \multirow{2}{*}{$\begin{array}{l}\text { MHC } \\
(\mu \mathrm{g} / \mathrm{mL})^{\mathrm{e})}\end{array}$} & \multirow{2}{*}{$\begin{array}{l}\text { MIC } \\
\left.(\mu \mathrm{g} / \mathrm{mL})^{\mathrm{f}}\right)\end{array}$} \\
\hline & & & 0\% TFE & $20 \%$ TFE & PG & PC & & \\
\hline SB1 & KYKKALKKLAKLL & 13 & 12 & 63 & 60 & 45 & $>2000$ & 2 \\
\hline SB2 & kykkalkklakll & 13 & 9 & 69 & 70 & 30 & $>2000$ & 1 \\
\hline SB3 & *KYKKALKKLAKLL & 13 & n.d. & n.d. & n.d. & n.d. & n.d. & n.d. \\
\hline SB4 & *kykkalkklakll & 13 & 11 & 68 & 41 & 10 & 1000 & 4 \\
\hline SB5 & *ykkalkklakll & 12 & 11 & 66 & 76 & 11 & 500 & 8 \\
\hline SB6 & *kykkalkklakl & 12 & 12 & 48 & 60 & 0 & $>2000$ & 64 \\
\hline SB7 & *kykkalkklak & 11 & 11 & 33 & 6 & 2 & $>2000$ & $>64$ \\
\hline SB8 & *kkalkklakll & 11 & 13 & 53 & 57 & 3 & $>2000$ & 32 \\
\hline SB9 & *ykkalkklakl & 11 & 11 & 47 & 70 & 1 & $>2000$ & 64 \\
\hline SB10 & *llkalkklakkyk & 13 & 9 & 60 & 37 & 4 & 1000 & n.d. \\
\hline SB11 & *llkalkklakky & 12 & 11 & 64 & 49 & 10 & 1000 & 16 \\
\hline SB12 & *lkalkklakkyk & 12 & 9 & 42 & 25 & 0 & $>2000$ & 64 \\
\hline SB13 & *kalkklakkyk & 11 & 10 & 29 & 3 & 0 & $>2000$ & 64 \\
\hline SB14 & *llkalkklakk & 11 & 11 & 56 & 22 & 1 & $>2000$ & 32 \\
\hline SB15 & *lkalkklakky & 11 & 11 & 50 & 61 & 1 & $>2000$ & 32 \\
\hline SB16 & Ac-kykkalkklakll & 13 & 13 & 63 & 75 & 32 & 500 & 2 \\
\hline SB17 & Pr-kykkalkklakll & 13 & 15 & 68 & 71 & 35 & 500 & 2 \\
\hline SB18 & C8-kykkalkklakll & 13 & 14 & 60 & 31 & 99 & 16 & 2 \\
\hline
\end{tabular}

a) Single letter code for amino acids, * indicates a C-fucosyl group as shown in Scheme 1. Ac=acetyl, Pr=propyl,

$\mathrm{C}_{8}=$ octanoyl. b) Number of amino acids. c) $\mathrm{CD}$ spectra were recorded at $0.1 \mu \mathrm{g} / \mathrm{mL}$ in aq. $10 \mathrm{mM}$ phosphate buffer $\mathrm{pH} 7.2$ with addition of $0,5,10,15$ and $20 \% \mathrm{v} / \mathrm{v}$ trifluoroethanol (TFE). The primary CD spectra were analyzed using DichroWeb, and the percentages of $\alpha$-helical signals were extracted. The full table is shown in the SI (Table S2). The Contin-LL method and reference set 4 were used.(43) n.d. = not determined. d) Membrane disruption was assessed on phosphatidyl glycerol (PG) or phosphatidyl choline (PC) lipid vesicles loaded with $50 \mathrm{mM} \mathrm{5(6)-carboxyfluorescein} \mathrm{buffer} \mathrm{and} \mathrm{treated} \mathrm{with} \mathrm{peptide}$ solutions (45 s) and 1.2\% Triton X-100 (285 s). The percentage of lysis at $10 \mu \mathrm{g} / \mathrm{mL}$ was determined as $\mathrm{I}_{\mathrm{t}} / \mathrm{I}_{\infty}$ where $\mathrm{I}_{\mathrm{t}}$ is the fluorescence intensity at $\mathrm{t}=250 \mathrm{~s}$ and $\mathrm{I}_{\infty}$ is the fluorescence at $\mathrm{t}=350 \mathrm{~s}$. e) Minimum hemolytic concentration (MHC, $\mu \mathrm{g} / \mathrm{mL}$ ) was measured on human red blood cells in phosphate buffered saline at room temperature for 4 hours. All experiments were done in at least two independent duplicates. f) Minimum inhibitory concentration (MIC, $\mu \mathrm{g} / \mathrm{mL}$ ) was measured in Mueller-Hinton medium on P. aeruginosa PAO1, after incubation for $16-20 \mathrm{~h}$ at $37^{\circ} \mathrm{C}$. Values were obtained from at least 2 independent duplicate experiments giving the same results. 
a)

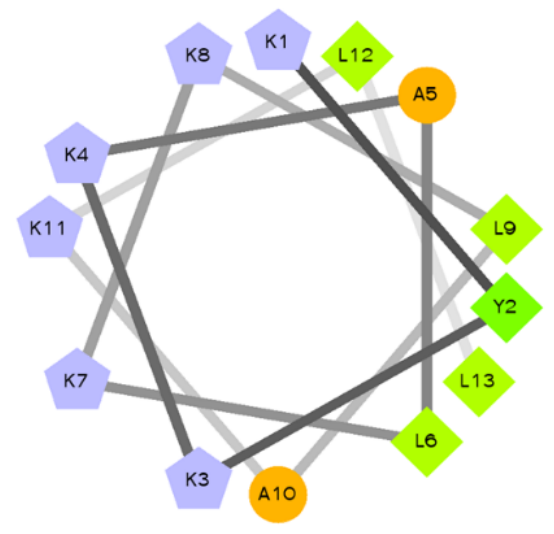

c)

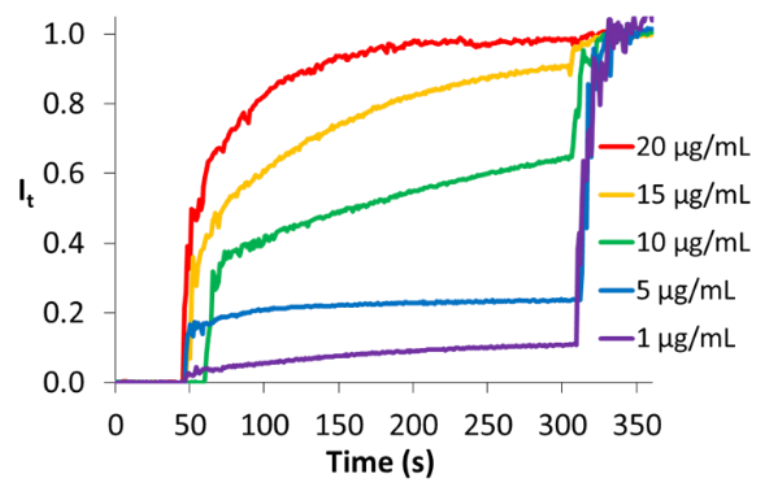

b)

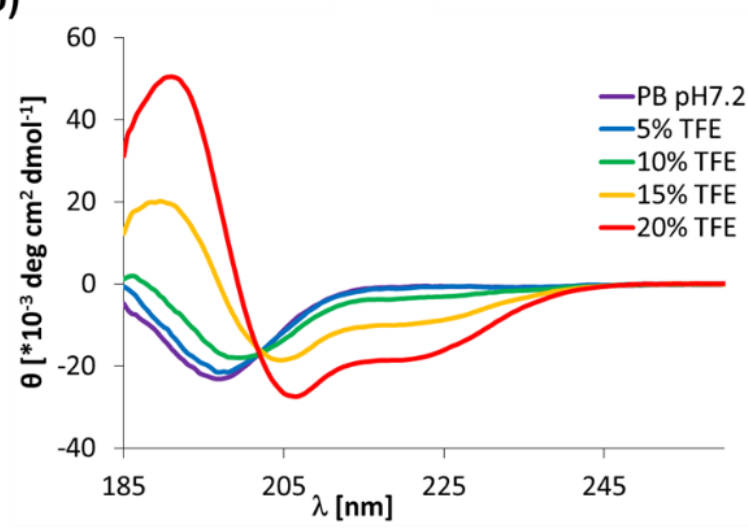

d)

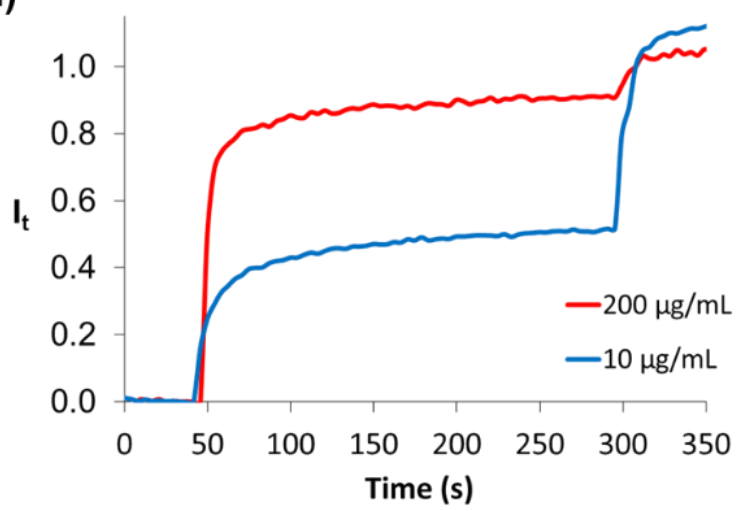

Figure 1. Evidence for $\alpha$-helical folding and membrane disruption by the 13-residue AMP SB1. a) Prediction of SB1 with $\alpha$-helix wheel. b) CD spectra of SB1 in phosphate buffer $\mathrm{pH} 7.2$ with 0, 5, 10, 15 and 20\% v/v 2,2,2trifluoroethanol. 5(6)-Carboxyfluorescein leakage from c) phosphatidylglycerol (PG) and d) phosphatidylcholine (PC) lipid vesicles. Addition of SB1 to a lipid vesicle solution in buffer (10 mM TRIS, $107 \mathrm{mM} \mathrm{NaCl}, \mathrm{pH} 7.4)$ at $45 \mathrm{~s}$ and addition of $1.2 \%$ Triton $\mathrm{X}-100$ at $285 \mathrm{~s}$.

\section{Fucosylated D-peptide SB4 is a membrane disruptive AMP}

The N-terminally fucosylated D-enantiomeric sequence SB4 and the fucosylated retro-inverso sequence SB10 showed a folding and membrane disruptive behavior similar to the parent sequence SB1 (Table 1, Figure S1, Supplementary Table S2 and Figure S3). $\alpha$-Helical folding was significantly reduced upon sequential removal of leucine residues at the C-terminus $(\mathbf{S B 4} \rightarrow \mathbf{S B 6} \rightarrow \mathbf{S B 7})$ respectively at the N-terminus of the retro-inverso sequence $(\mathbf{S B 1 0} \rightarrow \mathbf{S B 1 2} \rightarrow \mathbf{S B 1 3})$, in agreement with the $\alpha$-helix propensity of leucine. Furthermore, membrane disruption as measured by vesicle leakage was strongly reduced for SB7 and SB13 
lacking both terminal leucine residues and showing negligible $\alpha$-helical folding with TFE. None of the fucosylated sequences showed any significant hemolysis. Remarkably, the fucosylated analog SB4 of the parent AMP showed the same minimum inhibitory concentration (MIC) against $P$. aeruginosa PAO1 as the parent AMP, however the activity was strongly reduced in all modified sequences. Taken together, these data showed that the fucosylated AMP SB4 behaved as a membrane disruptive AMP similarly to the parent sequence.

\section{SB4 forms a four-helix bundle as LecB complex}

Crystallization attempts with the full sequence SB1 or its D-enantiomer SB2, the racemic mixture of both, or with the fucosylated L-enantiomer SB3 in complex with LecB were unsuccessful. By contrast, we obtained good quality diffraction data of LecB complexes with the fucosylated analog SB4 (2.01 А, PDB 6Q86, Table S4.1 and Figure 2, and 2.01 6Q79, Supplementary Table S3, Table S4.2 and Figure S5.2). In these two structures, SB4 peptides are bound to LecB monomers at their fucose binding sites via the $\mathrm{N}$-terminal fucose and folded into fully or partially resolved amphiphilic $\alpha$-helices, with two (PDB 6Q86) respectively four (PDB 6Q79) non-equivalent SB4 peptides in the asymmetric unit. In both structures, there are no contacts between the peptide portion of the ligands and the protein, suggesting that folding occurs independently of the lectin. The two respectively four nonequivalent $\alpha$-helices form four-helix bundles in which hydrophobic residues are packed on the inside and cationic, hydrophilic residues face outwards. In the first structure (PDB 6Q86), the four peptides forming the bundle are complete. However, in the second case (PDB 6Q79), only two of the $\alpha$-helices are entirely resolved and well-formed, while the other two are only 
observed for the six $\mathrm{N}$-terminal residues preceding the fucosyl group, which can be interpreted in terms of a partially folded $\alpha$-helix with a disordered C-terminus.
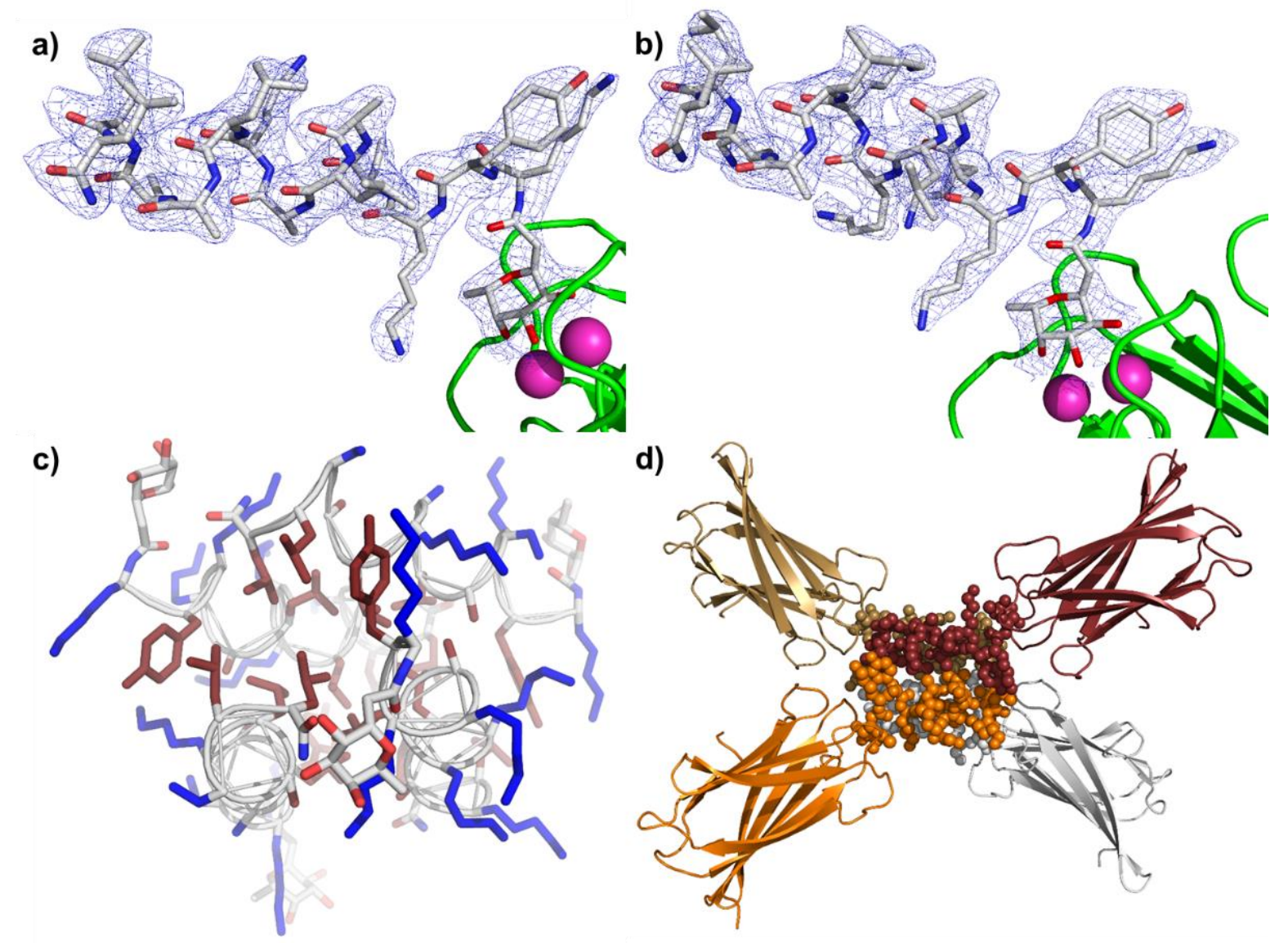

Figure 2. Details of the first X-ray structure of the SB4· LecB complex (PBD 6Q86) (a-b) The two nonequivalent peptides with electron density map as blue mesh, $\mathrm{Ca}^{2+}$ atoms shown as magenta spheres and the bound LecB monomer as green cartoon. (c) Charge distribution within the 4-helix bundle. Hydrophobic side chains are colored brown and cationic side chains in blue. Backbone atoms are shown as cartoon. (d) Overview of the 4-helix bundle in the crystal. Each of the four peptide (spheres) - LecB monomer (cartoon) complexes is independently color-coded.

\section{SB4 analogs form helix-bundles or extended structures as LecB complexes}

We next investigated shortened and retro-inverso sequences SB5-SB15 to test if additional peptide conformations might occur in LecB complexes besides the fully and partially folded $\alpha$-helices observed in the two structures of SB4-LecB. While we did not obtain any crystals for the least helical and inactive peptides SB7 and SB13, or for SB9 and SB14 which also 
belonged to the shortest and least helical sequences, the remaining seven fucosylated Dpeptides SB5, SB6, SB8, SB10, SB11, SB12 and SB15 yielded well diffracting crystals as complexes with LecB (Supplementary Table S3, Tables S4.3-4.10). These crystals revealed one to four different individual peptide structures each depending on crystal symmetry. In most cases the entire peptide sequence was well resolved (Supplementary Figures S5.3-5.10, Figure 3).

A detailed analysis of peptide conformations in the different structures showed that almost all residues were in an $\alpha$-helical conformation as indicated by their Ramachandran angles (Supplementary Table S5). LecB complexes with SB5, SB6, SB8, SB10 and SB11 were globally comparable to the two SB4 $\cdot$ LecB structures and showed $\alpha$-helical peptides engaging in two-helix or four-helix bundles with a hydrophobic core and hydrophilic residues on the outside (Supplementary Figures S5.3-5.8). As observed with SB4 the helices did not form significant contacts with LecB. In fact, for two of the four $\alpha$-helices in the bundle formed by SB10, the fucosyl group did not even bind to the lectin and the corresponding helix was only held in place by hydrophobic contacts within the bundle (Figure 3a, b, c). On the other hand, peptides SB12 and SB15 were observed in an extended, $\beta$-sheet like conformation engaging in four H-bonding contacts with LecB, providing a direct picture of an alternative, unfolded conformation (Figure 3d, e, f and Supplementary Figures S5.9-5.10). Both of these sequences belonged to the retro-inverso series and showed a less complete $\alpha$-helical folding in $20 \%$ TFE compared to the parent AMP, which might explain the absence of $\alpha$-helical folding in the crystal (Table 1). 
a)

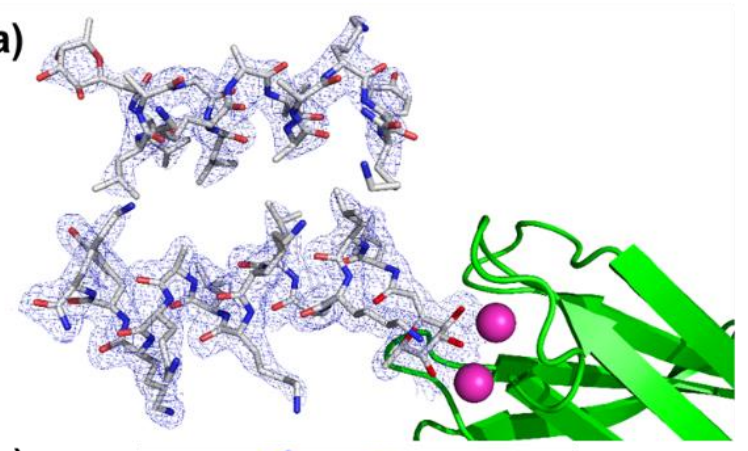

b)

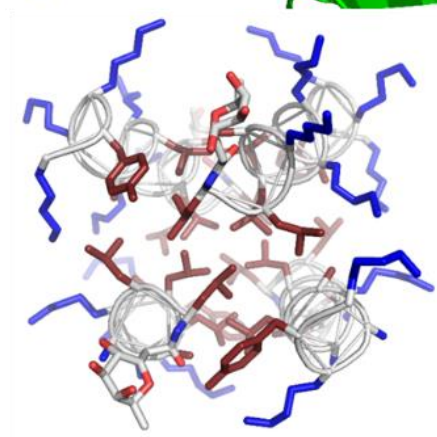

c)

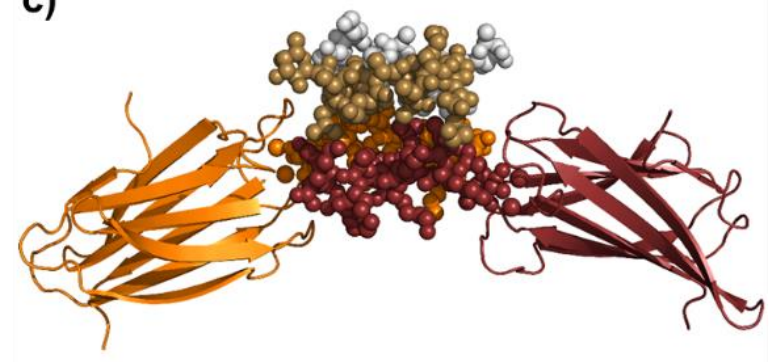

d)

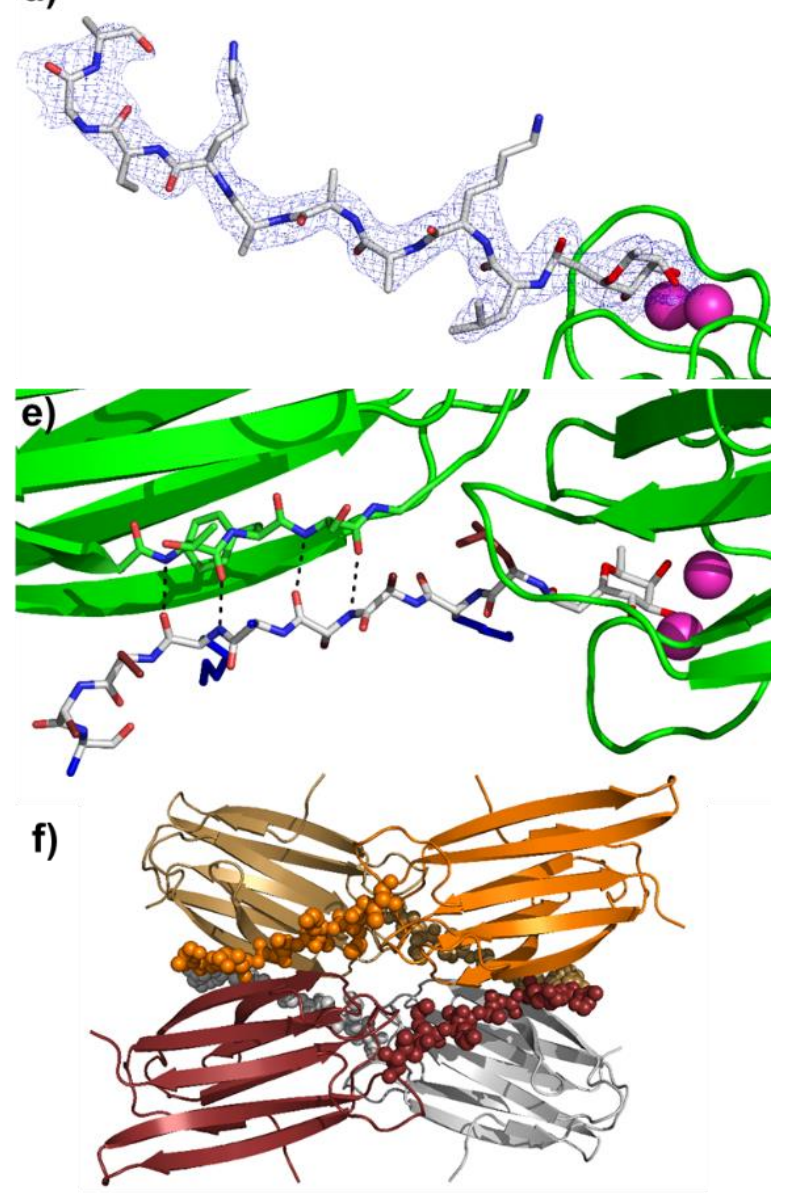

Figure 3. Details of the X-ray structures of $\alpha$-helical AMPs in complex with LecB. (a) Electron density map of SB10, with $\mathrm{Ca}^{2+}$ atoms shown as magenta spheres and the bound LecB monomer as green cartoon. (b) Charge distribution within the 4-helix bundle formed by SB10. Backbone atoms are shown as cartoon. Hydrophobic side chains are colored brown and cationic side chains in blue. (c) 4-helix bundle of peptide SB10. Peptides are shown as spheres and bound lectin monomers are displayed as cartoon of the same color. (d) Electron density map of SB15 as in (a). (e) Details of the four stabilizing hydrogen bonds (black dashes) engaged on a LecB monomer by peptide SB15. Hydrophobic side chains are colored brown and cationic side chains in blue. (f) $\beta$ sheet engagement of peptide SB15 bound to LecB. Peptides are shown as spheres and bound lectin monomers are displayed as cartoon of the same color. 


\section{SB4 $\alpha$-helices are stabilized by bundle formation in the crystal}

The ten crystal structures from eight different peptides described above revealed twenty-four individual structures of short (11 to 13 residues) peptides. Assuming that all unresolved residues reflect disordered conformations, the overall $\alpha$-helix content across all twenty-four resolved structures amounts to $76 \%$ on a per residue basis, which is significantly higher than the average $\alpha$-helical content calculated from CD spectra showing unfolded conformations in water, which corresponds to the crystal environment ( $\sim 10 \% \alpha$-helix content), and partially $\alpha$ helical conformations in the presence of TFE ( $\sim 58 \% \alpha$-helix content in $20 \%$ TFE).

Considering that there were almost no contacts between the peptides and the protein outside the fucose binding site in these structures, we hypothesized that $\alpha$-helices might be stabilized by helix bundle formation in the crystal.

To test this hypothesis, we performed MD simulations using GROMACS(45) in explicit water for $1000 \mathrm{~ns}$ at $300 \mathrm{~K}$ starting from the 4-helix bundle of peptide SB4 as observed in the X-ray structure (PDB 6Q86), or from a single isolated $\alpha$-helix. The 4-helix bundle was stable throughout the entire simulation as shown by overlays across the whole trajectory (Figure 4a), the stable number of hydrogen bonds and the low RMSD variance (Figure 4c/d, orange line). By contrast, the isolated $\alpha$-helix rapidly unfolded under the same conditions and transitioned to a conformation containing a disordered N-terminus, a turn and a short intramolecular $\beta$-sheet at the C-terminus (Figure $4 \mathrm{~b}$ and Figure $4 \mathrm{c} / \mathrm{d}$, blue line), which is consistent with CD data in water (Table 1 and Supplementary Table S2). The MD data thus clearly showed that the 4-helix bundle observed in the LecB crystal was stable on its own, and that its formation could explain the occurrence of $\alpha$-helical conformations in the aqueous environment of the protein crystal despite the fact that the sequence does not fold significantly in pure water. 
a)

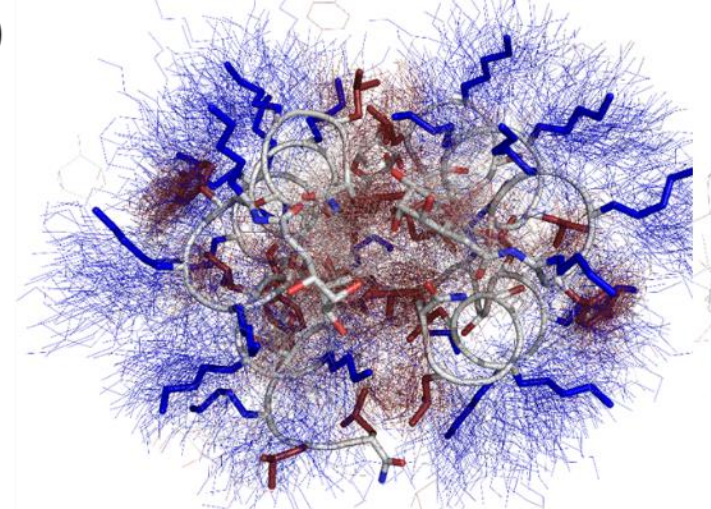

c)

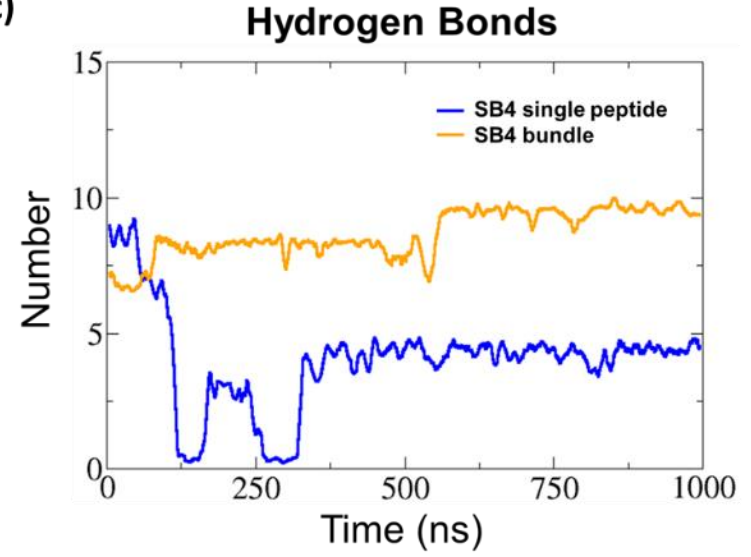

b)

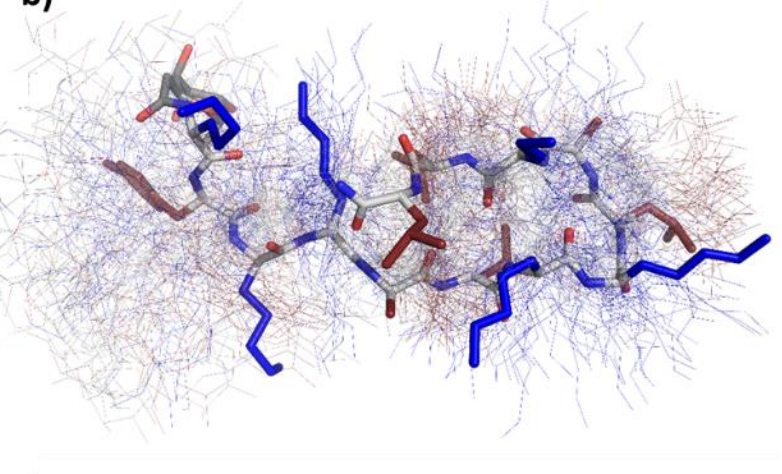

d)

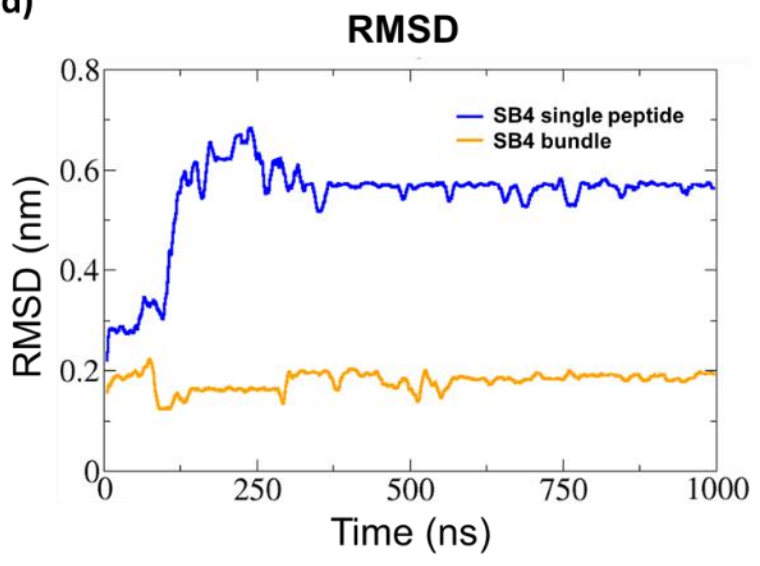

Figure 4. MD simulations of SB4 as 4-helix bundle and as single peptide in water. (a) Overlays of 100 states over the whole 1000 ns trajectory of a SB4 bundle. The average structure is shown as sticks, with the 100 overlayed states as thin lines. Hydrophobic side chains are colored brown and cationic side chains blue. Backbone atoms are represented as cartoon. (b) Overlay of the major conformations from the whole $1000 \mathrm{~ns}$ trajectory of SB4 as single peptide in water. The average structure is shown as large sticks, with overlayed states as thin lines. Hydrophobic side chains are colored brown and cationic side chains blue. (c) Intramolecular Hydrogen bonds of a single helix within the bundle against the single peptide in water. (d) Root Mean Square Distances of the backbone atoms relative to the backbone atoms of the starting model. 


\section{H-bonding to the $\mathrm{N}$-acyl group enhances $\alpha$-helix amphiphilicity}

The presence of the $\mathrm{C}$-fucosyl group might affect folding by enabling an additional $\alpha$-helical backbone H-bond interaction involving its linker amide carbonyl group, which is absent in the free peptide. The crystallographic data showed that this additional H-bond was indeed present in 10 out of 18 individual structures of $\alpha$-helical peptides, as illustrated here with the structure of LecB.SB6 which features both the H-bonded (Figure 5a) and the non H-bonded conformations (Figure 5b).

To test if this additional $\alpha$-helical $\mathrm{H}$-bond might also participate in folding in an isolated $\alpha$-helix, we performed MD simulations with SB2 and the C-fucosylated version SB4. We also investigated the N-acetyl (SB16), N-propanoyl (SB17) and N-octanoyl (SB18) derivatives, which we synthesized as new analogs of potential interest as antimicrobial peptides (Table 1). Indeed, although most AMPs have free $\mathrm{N}$-termini, $\mathrm{N}$-acylated AMPs can also show potent antimicrobial effects. $(7,46)$ We ran our MD simulations in explicit water solvent with $20 \% \mathrm{v} / \mathrm{v}$ TFE for $1000 \mathrm{~ns}$ starting from a model of each peptide in a pre-folded $\alpha$-helix conformation derived from the structure of SB4 (PDB 6Q86) including the additional H-bond with the $\mathrm{N}$-acyl group.

The N-fucosylated peptide SB4 rapidly lost its acyl H-bond in the course of the simulation, leading to N-terminal conformations related to those of the free peptide SB2. In this conformation the $\mathrm{N}$-terminal lysine side chain points to the opposite side of the $\alpha$-helix relative to the cluster of cationic side chains (Figure 5c, d, f). By contrast, The N-acyl H-bond was preserved across the entire MD trajectory in SB16 (Figure 5e, f), SB17 and SB18 (Supplementary Figures S6 and S7). These more stable trajectories resulted in an N-terminal conformation in which the lysine side chain at position 1 is rotated by $180^{\circ}$ compared to $\mathbf{S B 2}$ and SB4 and is located on the same side of the $\alpha$-helix as the other cationic side chains. This arrangement of the side chains corresponded to an increased $\alpha$-helix amphiphilicity compared 
to SB2 and SB4. The conservation of the N-acyl H-bond in SB16-SB18 also induced a more rigid conformation of the N-terminal lysine side chain compared to SB2 and SB4 (Figure 5g).
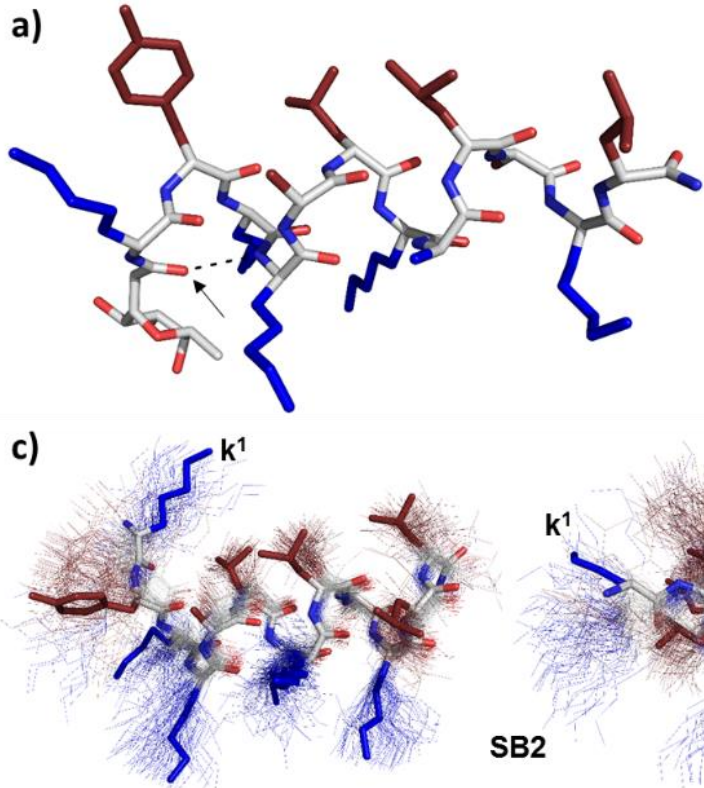

d)
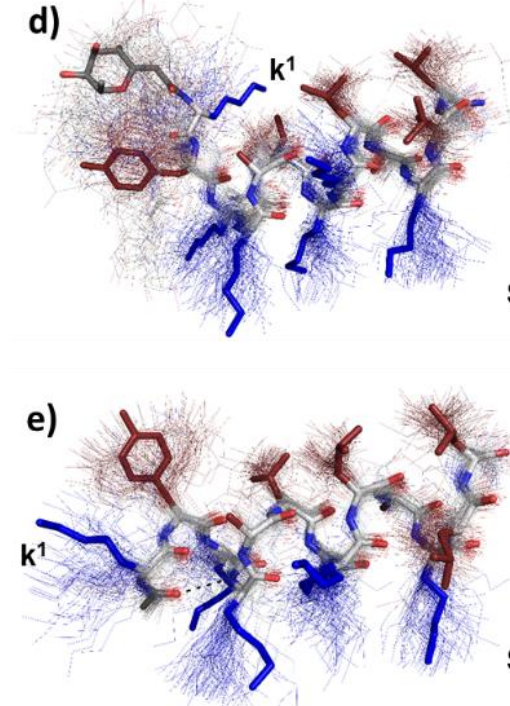

b)
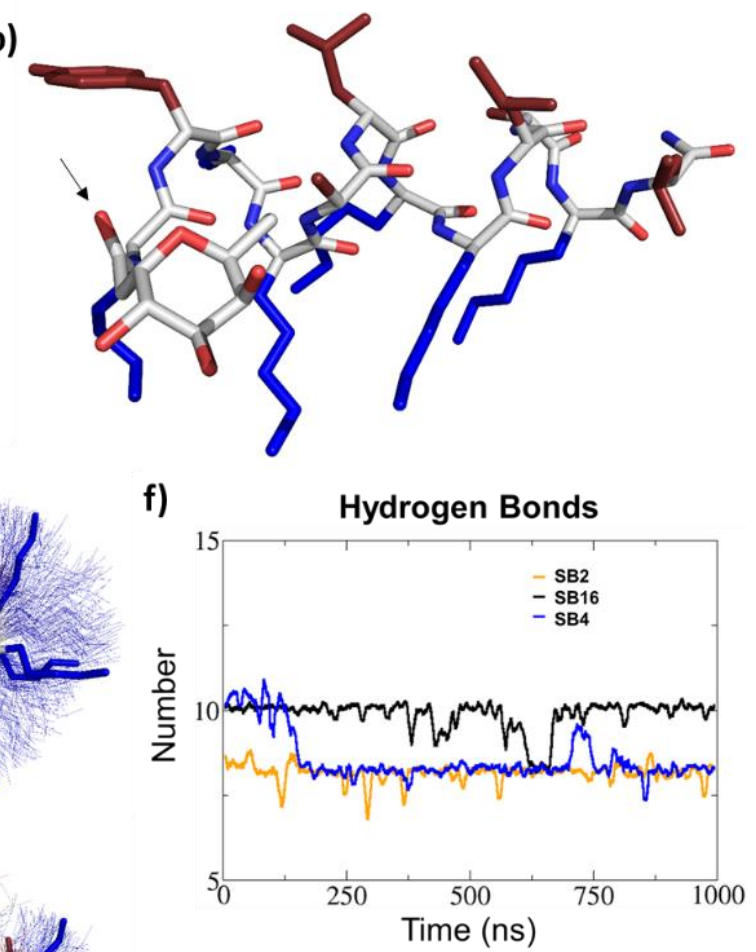

g)

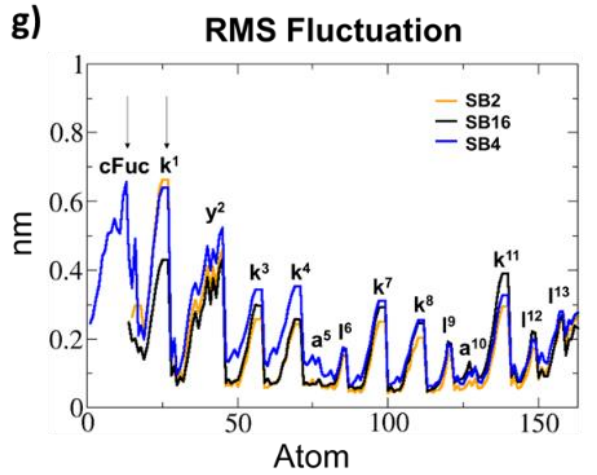

Figure 5. MD simulations with SB2, SB4 and SB16 in 20\% TFE. The two conformations of peptide SB6 (PDB 6Q6X) with (a) and without (b) the additional H-bond induced by the C-fucoside carbonyl moiety. Overlays of 100 states over the whole 1000 ns trajectories of SB2 (c), SB4 (d) and SB16 (e) respectively. The average structure is shown as large sticks, with the 100 overlayed states as thin lines. Hydrophobic side chains are colored brown and cationic side chains blue. (f) H-bond counts. The N-terminal acetyl group is taking part in an additional H-bond compared to the fucosylated and non-fucosylated peptides. (g) The Root Mean Square fluctuations per atom show the high flexibility of the C-fucosyl group (cFuc) and the first lysine residue $\left(\mathrm{k}^{1}\right)$ compared to the acetylated peptide. 


\section{$\mathrm{N}$-acylated analogs of SB2 are potent antimicrobial and antibiofilm agents}

Our initial screening had shown that fucosylated SB4 and the N-acylated SB16-SB18 were as active as SB2 in terms of membrane disruption and as AMPs against $P$. aeruginosa PAO1

(Table 1). This suggested that the N-terminal amino group in SB2 did not contribute significantly to activity, possibly because reduction by one positive charge was compensated by an increase in $\alpha$-helix amphiphilicity induced by the additional $\mathrm{H}$-bond as discussed above and pointed to the possibility to use $\mathrm{N}$-acylation to modulate AMP activity.

A survey of antimicrobial activity across additional pathogenic bacteria showed that N-acylated AMPs SB4 and SB16-SB18 were as active as SB2 across the different strains, and even slightly more active in the case of Klebsiella pneumoniae-S, a pathogen which is generally difficult to control. Increasing peptide hydrophobicity by an N-terminal octanoyl group resulted in AMP SB18 showing the strongest antimicrobial activity (Table 2), however this sequence was unselective and strongly hemolytic (Table 1). Note that the free, nonfucosylated D-peptide SB2 was slightly more active than its L-enantiomer SB1, which might reflect higher stability of the D-enantiomer in the culture medium where the L-enantiomer undergoes proteolysis (Supplementary Figure S2).

Table 2. Minimal inhibitory concentration data.

\begin{tabular}{lcccccc}
\hline & \multicolumn{7}{c}{ MIC $^{\text {a) }}$} \\
\hline Strain & SB1 & SB2 & SB4 & SB16 & SB17 & SB18 \\
\hline PAO1 & 2 & 1 & 4 & 2 & 2 & 2 \\
A. baumannii 19606 & 2 & 1 & 1 & 1 & 1 & 2 \\
K. pneumoniae-S & 32 & 16 & 16 & 8 & 8 & 4 \\
E. coli (W3110) & 1 & 0.5 & 1 & 1 & 1 & 2 \\
S. Epidermiditis & n.d. & 2 & 4 & 2 & 2 & 1 \\
MRSA* & n.d. & 4 & 8 & 4 & 4 & 2 \\
\hline
\end{tabular}

a) MIC (minimum inhibitory concentration) in $\mu \mathrm{g} / \mathrm{mL}$ against wild type Gram-negative, Gram-positive and multidrug resistant (MDR, marked*) were measured by $1 / 2$ serial dilutions on 96 well plates in Mueller-Hinton $(\mathrm{MH})$ broth after incubation overnight at $37^{\circ} \mathrm{C}$. MIC values were measured in independent duplicates with at least two experiments giving the same value. 
We further investigated inhibition of $P$. aeruginosa biofilms by SB4 since this peptide binds lectin LecB, and related multivalent $(33,39,47)$ and monovalent LecB ligands(48-50) have been shown to inhibit biofilms from this bacterium. Indeed, SB4 inhibited P. aeruginosa biofilm formation, however the effect was comparable to the free D-enantiomeric peptide SB2 (Figure 6). The L-enantiomer SB1 was again significantly less active against biofilms, probably due to proteolysis in the medium. We propose that the observed biofilm inhibition effect by SB2 and SB4 primarily results from a direct antibacterial effect mediated by membrane disruption. This hypothesis is supported by vesicle leakage experiments showing that both peptides induce significant membrane perturbations (Table 1).

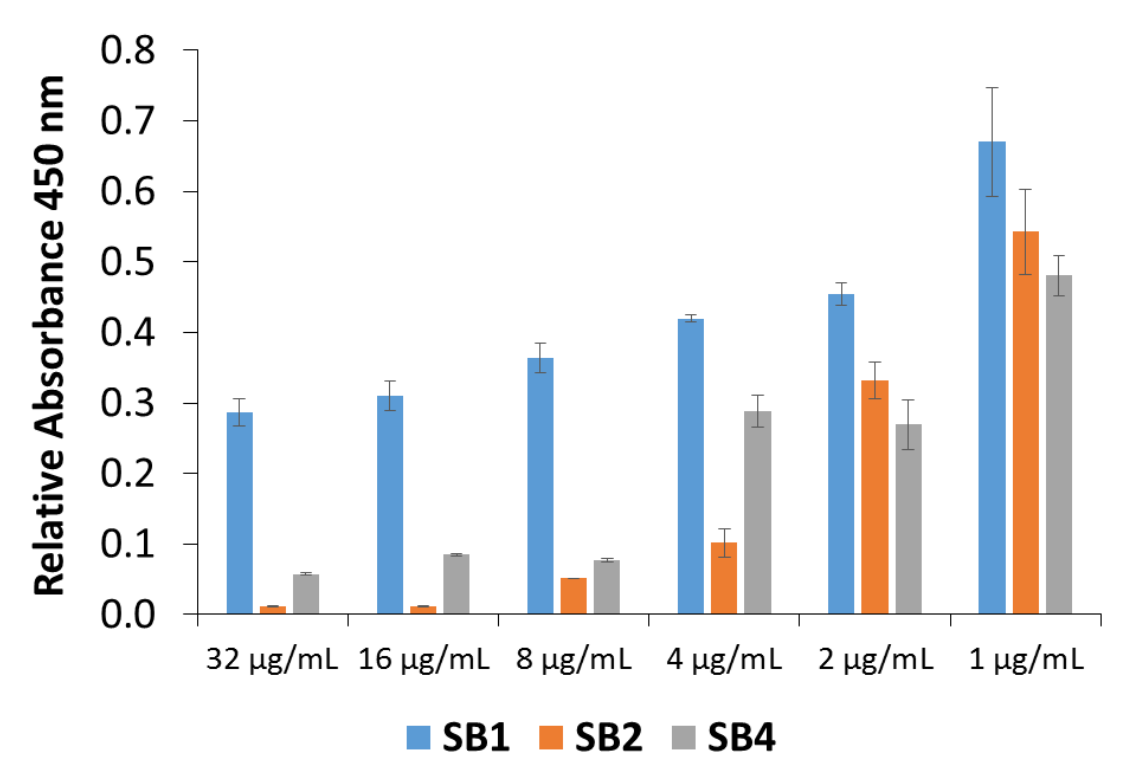

Figure 6. Relative absorbance readouts for Biofilm Inhibition on Pseudomonas aeruginosa PAO1 biofilm in M63 medium compared to untreated biofilms. Compound-containing wells were inoculated with the bacteria and the biofilms were allowed to grow $24-25$ hours at $37^{\circ}$ under static conditions. After washing, the biofilms were revealed with $0.5 \mathrm{mM}$ WST- 8 and $20 \mu \mathrm{M}$ phenazine ethosulfate for 3 hours and the absorbance measured. The experiments were performed as triplicates.

The membrane perturbation effects induced by SB2 and SB4 were further investigated by transmission electron microscopy (TEM). Images of P. aeruginosa, E. coli and A. baumannii cells showed that SB4 and SB2 induced similar morphological changes (Figure 7). After 
treatment of PAO1 and E. coli with the peptides, vesicle-like structures and blebs were observed around the cells (blue arrows), consistent with a membrane disruptive mechanism. Peptides SB2 and SB4 also similarly affected the pili of A. baumannii (black arrows), one of its key virulence factors. In PAO1 and A. baumannii, dense aggregates were formed within the bacteria (orange arrows), which can be explained by peptide accumulation inside the cell and possibly aggregation with DNA.
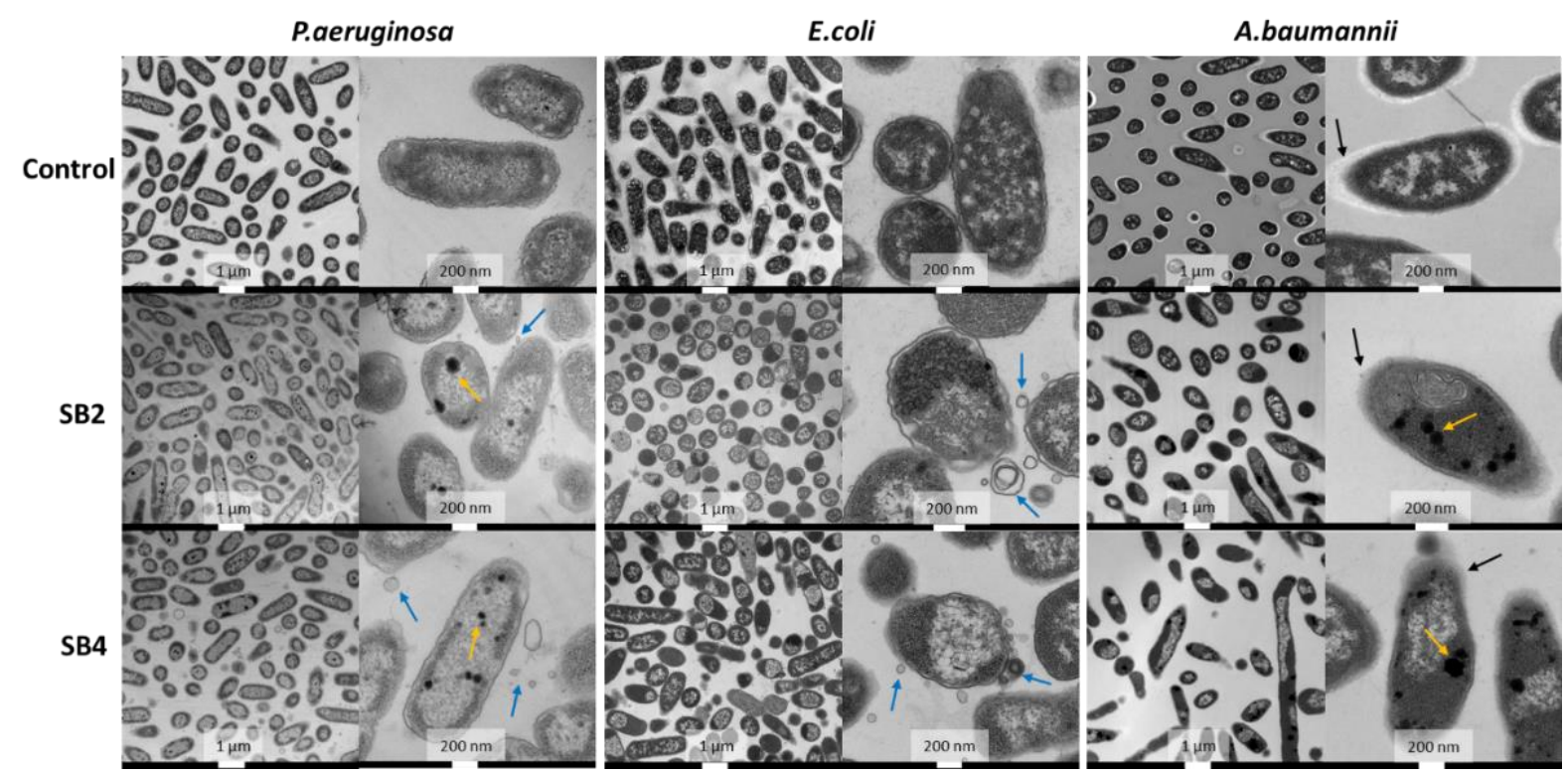

Figure 7. TEM images on Pseudomonas aeruginosa PAO1, E. coli and A. baumannii treated with $40 \mu \mathrm{g} / \mathrm{mL}$ SB2 and $40 \mu \mathrm{g} / \mathrm{mL} \mathrm{SB4}$ after $60 \mathrm{~min}$. Arrows indicate effects of the peptides on bacterial membranes (blue arrows: vesicle like structures and blebs), cell contents (orange arrows: dense aggregates), and pili (black arrows: pili well present in control but less so in peptide treated cells). See Figure S4 for enlarged versions of the images.

\section{Conclusion}

Here we reported the first X-ray crystal structures of short $\alpha$-helical AMPs at the example of analogs of the 13-residue AMP SB1. The structures were obtained in form of complexes of the fucosylated D-enantiomeric sequence SB4 with the bacterial lectin LecB. We also investigated shortened and retro-inverso sequences, resulting in a total of twenty-four 
individual structures of eight different peptides. These structures show that these short AMPs form $\alpha$-helices which assemble as two-helix or four-helix bundles displaying hydrophobic residues on the inside and cationic residues on the outside, without significant interaction with the lectin except for the anchoring fucosyl group bound at the fucose binding site. In two cases the peptide is observed in an extended $\beta$-sheet like conformation making four $\mathrm{H}$ bonding interaction with residues on the lectin surface. Overall $76 \%$ of the residues are observed within an $\alpha$-helix, while the remaining residues are either not visible or in a different conformation. Molecular dynamics (MD) simulations show that $\alpha$-helices are stabilized by bundle formation and suggest that the $\mathrm{N}$-terminal acyl group present in the linker to the fucosyl group can extend the helix by one additional H-bond and increase $\alpha$-helix amphiphilicity. Indeed, several N-acylated AMP displayed equivalent or stronger antibacterial effects compared to the free peptide.

\section{Methods}

Procedures for peptide synthesis, CD-spectroscopy, vesicle leakage experiments, microbiology, crystallization, X-ray data collection and refinement statistics, molecular dynamics, transmission electron microscopy, and analytical data for all peptides, are described in the supporting information.

\section{Associated Content}

Supporting Information. The supporting information is available free of charge on the ACS Publication website. Synthesis and characterization of all peptides, X-ray data collection tables, detailed procedures for CD spectroscopy, vesicle leakage experiments, molecular dynamics, microbiology (MIC and biofilm assays) and transition electron microscopy. 
Accession Codes. Coordinates and structure factors of refined LecB complexed with fucosylated peptides are available from the Protein Data Bank with accession codes 6Q86 and 6Q79 (SB4), 6Q6W (SB5), 6Q6X (SB6), 6Q8G (SB8), 6Q8H and 6Q87 (SB10), 6Q85 (SB11), 6Q77 (SB12) and 6Q8D (SB15).

\section{Author Information}

Corresponding Author. *E-mail: jean-louis.reymond@ dcb.unibe.ch.

Author Contributions. SB synthesized peptides, performed X-ray crystallography and molecular dynamics, interpreted data and wrote the paper. BHG performed TEM studies and interpreted data. TNS performed vesicle leakage and antimicrobial activity assays. RV performed X-ray crystallography. MR synthesized peptides. SJ designed and supervised MD studies, interpreted data and wrote the paper. TD and JLR designed and supervised the study, interpreted data and wrote the paper.

Notes. The authors declare no competing financial interest.

\section{Acknowledgments}

This work was supported financially by the Swiss National Science Foundation. We thank the staff at the Swiss Light Source, Beamline X06DA (PXIII), Villigen, Switzerland, for support during data collection. 


\section{References}

1. O'Connell, K. M. G., Hodgkinson, J. T., Sore, H. F., Welch, M., Salmond, G. P. C., and Spring, D. R. (2013) Combating Multidrug-Resistant Bacteria: Current Strategies for the Discovery of Novel Antibacterials, Angew. Chem., Int. Ed. Engl. 52, 1070610733.

2. Tommasi, R., Brown, D. G., Walkup, G. K., Manchester, J. I., and Miller, A. A. (2015) ESKAPEing the labyrinth of antibacterial discovery, Nat. Rev. Drug Discovery $14,529-542$.

3. Fleeman, R., LaVoi, T. M., Santos, R. G., Morales, A., Nefzi, A., Welmaker, G. S., Medina-Franco, J. L., Giulianotti, M. A., Houghten, R. A., and Shaw, L. N. (2015) Combinatorial Libraries As a Tool for the Discovery of Novel, Broad-Spectrum Antibacterial Agents Targeting the ESKAPE Pathogens, J. Med. Chem. 58, 33403355 .

4. Zasloff, M. (2002) Antimicrobial peptides of multicellular organisms, Nature 415, 389-395.

5. Nguyen, L. T., Haney, E. F., and Vogel, H. J. (2011) The expanding scope of antimicrobial peptide structures and their modes of action, Trends in Biotechnology 29, 464-472.

6. Mojsoska, B., and Jenssen, H. (2015) Peptides and Peptidomimetics for Antimicrobial Drug Design, Pharmaceuticals (Basel) 8, 366-415.

7. Blondelle, S. E., and Houghten, R. A. (1992) Design of model amphipathic peptides having potent antimicrobial activities, Biochemistry 31, 12688-12694.

8. Javadpour, M. M., Juban, M. M., Lo, W. C., Bishop, S. M., Alberty, J. B., Cowell, S. M., Becker, C. L., and McLaughlin, M. L. (1996) De novo antimicrobial peptides with low mammalian cell toxicity, J. Med. Chem. 39, 3107-3113. 
9. Bechinger, B. (1999) The structure, dynamics and orientation of antimicrobial peptides in membranes by multidimensional solid-state NMR spectroscopy, Biochim. Biophys. Acta 1462, 157-183.

10. Scott, M. G., Yan, H., and Hancock, R. E. (1999) Biological properties of structurally related alpha-helical cationic antimicrobial peptides, Infect. Immun. 67, 2005-2009.

11. Yang, L., Harroun, T. A., Weiss, T. M., Ding, L., and Huang, H. W. (2001) Barrelstave model or toroidal model? A case study on melittin pores, Biophys. J. 81, 14751485.

12. Brogden, K. A. (2005) Antimicrobial peptides: pore formers or metabolic inhibitors in bacteria?, Nature Rev. Microbiol. 3, 238-250.

13. Kang, S. J., Won, H. S., Choi, W. S., and Lee, B. J. (2009) De novo generation of antimicrobial LK peptides with a single tryptophan at the critical amphipathic interface, J. Pept. Sci. 15, 583-588.

14. Yin, L. M., Edwards, M. A., Li, J., Yip, C. M., and Deber, C. M. (2012) Roles of hydrophobicity and charge distribution of cationic antimicrobial peptides in peptidemembrane interactions, J. Biol. Chem. 287, 7738-7745.

15. Li, A., Lee, P. Y., Ho, B., Ding, J. L., and Lim, C. T. (2007) Atomic force microscopy study of the antimicrobial action of Sushi peptides on Gram negative bacteria, Biochim. Biophys. Acta 1768, 411-418.

16. Shaw, J. E., Epand, R. F., Hsu, J. C., Mo, G. C., Epand, R. M., and Yip, C. M. (2008) Cationic peptide-induced remodelling of model membranes: direct visualization by in situ atomic force microscopy, J. Struct. Biol. 162, 121-138.

17. Zhu, X., Shan, A., Ma, Z., Xu, W., Wang, J., Chou, S., and Cheng, B. (2015) Bactericidal efficiency and modes of action of the novel antimicrobial peptide T9W against Pseudomonas aeruginosa, Antimicrob. Agents Chemother. 59, 3008-3017. 
18. Strandberg, E., and Ulrich, A. S. (2015) AMPs and OMPs: Is the folding and bilayer insertion of beta-stranded outer membrane proteins governed by the same biophysical principles as for alpha-helical antimicrobial peptides?, Biochim. Biophys. Acta 1848, 1944-1954.

19. Mohamed, M. F., Brezden, A., Mohammad, H., Chmielewski, J., and Seleem, M. N. (2017) A short D-enantiomeric antimicrobial peptide with potent immunomodulatory and antibiofilm activity against multidrug-resistant Pseudomonas aeruginosa and Acinetobacter baumannii, Sci. Rep. 7, 6953.

20. Kim, M. K., Kang, H. K., Ko, S. J., Hong, M. J., Bang, J. K., Seo, C. H., and Park, Y. (2018) Mechanisms driving the antibacterial and antibiofilm properties of Hp1404 and its analogue peptides against multidrug-resistant Pseudomonas aeruginosa, Sci. Rep. $8,1763$.

21. Torres, M. D. T., Pedron, C. N., Higashikuni, Y., Kramer, R. M., Cardoso, M. H., Oshiro, K. G. N., Franco, O. L., Silva Junior, P. I., Silva, F. D., Oliveira Junior, V. X., Lu, T. K., and de la Fuente-Nunez, C. (2018) Structure-function-guided exploration of the antimicrobial peptide polybia-CP identifies activity determinants and generates synthetic therapeutic candidates, Commun. Biol. 1, 221.

22. Haney, E. F., Hunter, H. N., Matsuzaki, K., and Vogel, H. J. (2009) Solution NMR studies of amphibian antimicrobial peptides: linking structure to function?, Biochim. Biophys. Acta 1788, 1639-1655.

23. Powers, J. P., and Hancock, R. E. (2003) The relationship between peptide structure and antibacterial activity, Peptides 24, 1681-1691.

24. Liu, S., Wang, F., Tang, L., Gui, W., Cao, P., Liu, X., Poon, A. W., Shaw, P. C., and Jiang, T. (2007) Crystal structure of mastoparan from Polistes jadwagae at $1.2 \mathrm{~A}$ resolution, J. Struct. Biol. 160, 28-34.

25. Terwilliger, T. C., and Eisenberg, D. (1982) The structure of melittin. II. Interpretation of the structure, J. Biol. Chem. 257, 6016-6022. 
26. Hayouka, Z., Mortenson, D. E., Kreitler, D. F., Weisblum, B., Forest, K. T., and Gellman, S. H. (2013) Evidence for phenylalanine zipper-mediated dimerization in the X-ray crystal structure of a magainin 2 analogue, J. Am. Chem. Soc. 135, 1573815741.

27. Toniolo, C., Bonora, G. M., Bavoso, A., Benedetti, E., di Blasio, B., Pavone, V., and Pedone, C. (1985) Molecular structure of peptaibol antibiotics: solution conformation and crystal structure of the octapeptide corresponding to the 2-9 sequence of emerimicins III and IV, J. Biomol. Struct. Dyn. 3, 585-598.

28. Aravinda, S., Shamala, N., and Balaram, P. (2008) Aib residues in peptaibiotics and synthetic sequences: analysis of nonhelical conformations, Chem. Biodivers. 5, 12381262.

29. Karle, I. L., and Balaram, P. (1990) Structural characteristics of alpha-helical peptide molecules containing Aib residues, Biochemistry 29, 6747-6756.

30. Zhang, L., Parente, J., Harris, S. M., Woods, D. E., Hancock, R. E. W., and Falla, T. J. (2005) Antimicrobial Peptide Therapeutics for Cystic Fibrosis, Antimicrob. Agents Chemother. 49, 2921-2927.

31. Mitchell, E., Houles, C., Sudakevitz, D., Wimmerova, M., Gautier, C., Perez, S., Wu, A. M., Gilboa-Garber, N., and Imberty, A. (2002) Structural basis for oligosaccharidemediated adhesion of Pseudomonas aeruginosa in the lungs of cystic fibrosis patients, Nat. Struct. Biol. 9, 918-921.

32. Roethlisberger, P., Istrate, A., Marcaida Lopez, M. J., Visini, R., Stocker, A., Reymond, J. L., and Leumann, C. J. (2016) X-ray structure of a lectin-bound DNA duplex containing an unnatural phenanthrenyl pair, Chem. Commun., doi: $10.1039 / \mathrm{c} 1036 \mathrm{cc} 00374 \mathrm{e}$.

33. Johansson, E. M., Crusz, S. A., Kolomiets, E., Buts, L., Kadam, R. U., Cacciarini, M., Bartels, K. M., Diggle, S. P., Camara, M., Williams, P., Loris, R., Nativi, C., Rosenau, F., Jaeger, K. E., Darbre, T., and Reymond, J. L. (2008) Inhibition and dispersion of 
Pseudomonas aeruginosa biofilms by glycopeptide dendrimers targeting the fucosespecific lectin LecB, Chem Biol 15, 1249-1257.

34. Kadam, R. U., Bergmann, M., Hurley, M., Garg, D., Cacciarini, M., Swiderska, M. A., Nativi, C., Sattler, M., Smyth, A. R., Williams, P., Camara, M., Stocker, A., Darbre, T., and Reymond, J. L. (2011) A glycopeptide dendrimer inhibitor of the galactosespecific lectin LecA and of Pseudomonas aeruginosa biofilms, Angew. Chem., Int. Ed. Engl. 50, 10631-10635.

35. Kadam, R. U., Bergmann, M., Garg, D., Gabrieli, G., Stocker, A., Darbre, T., and Reymond, J. L. (2013) Structure-based optimization of the terminal tripeptide in glycopeptide dendrimer inhibitors of Pseudomonas aeruginosa biofilms targeting LecA, Chem. Eur. J. 19, 17054-17063.

36. Kadam, R. U., Garg, D., Schwartz, J., Visini, R., Sattler, M., Stocker, A., Darbre, T., and Reymond, J. L. (2013) CH-pi "T-Shape" Interaction with Histidine Explains Binding of Aromatic Galactosides to Pseudomonas aeruginosa lectin LecA, ACS Chem. Biol. 8, 1925-1930.

37. Visini, R., Jin, X., Bergmann, M., Michaud, G., Pertici, F., Fu, O., Pukin, A., Branson, T. R., Thies-Weesie, D. M., Kemmink, J., Gillon, E., Imberty, A., Stocker, A., Darbre, T., Pieters, R. J., and Reymond, J. L. (2015) Structural Insight into Multivalent Galactoside Binding to Pseudomonas aeruginosa Lectin LecA, ACS Chem. Biol. 10, 2455-2462.

38. Bergmann, M., Michaud, G., Visini, R., Jin, X., Gillon, E., Stocker, A., Imberty, A., Darbre, T., and Reymond, J. L. (2016) Multivalency effects on Pseudomonas aeruginosa biofilm inhibition and dispersal by glycopeptide dendrimers targeting lectin LecA, Org. Biomol. Chem. 14, 138-148.

39. Michaud, G., Visini, R., Bergmann, M., Salerno, G., Bosco, R., Gillon, E., Richichi, B., Nativi, C., Imberty, A., Stocker, A., Darbre, T., and Reymond, J.-L. (2016) Overcoming antibiotic resistance in Pseudomonas aeruginosa biofilms using glycopeptide dendrimers, Chem. Sci. 7, 166-182. 
40. He, R., Di Bonaventura, I., Visini, R., Gan, B. H., Fu, Y., Probst, D., Luscher, A., Kohler, T., van Delden, C., Stocker, A., Hong, W., Darbre, T., and Reymond, J. L. (2017) Design, crystal structure and atomic force microscopy study of thioether ligated d,1-cyclic antimicrobial peptides against multidrug resistant Pseudomonas aeruginosa, Chem. Sci. 8, 7464-7475.

41. Di Bonaventura, I., Jin, X., Visini, R., Probst, D., Javor, S., Gan, B.-H., Michaud, G., Natalello, A., Doglia, S. M., Kohler, T., van Delden, C., Stocker, A., Darbre, T., and Reymond, J.-L. (2017) Chemical space guided discovery of antimicrobial bridged bicyclic peptides against Pseudomonas aeruginosa and its biofilms, Chem. Sci. 8, 6784-6798.

42. Kolomiets, E., Johansson, E. M., Renaudet, O., Darbre, T., and Reymond, J. L. (2007) Neoglycopeptide dendrimer libraries as a source of lectin binding ligands, Org. Lett. 9, 1465-1468.

43. Sreerama, N., and Woody, R. W. (2000) Estimation of protein secondary structure from circular dichroism spectra: comparison of CONTIN, SELCON, and CDSSTR methods with an expanded reference set, Anal. Biochem. 287, 252-260.

44. Jasanoff, A., and Fersht, A. R. (1994) Quantitative determination of helical propensities from trifluoroethanol titration curves, Biochemistry 33, 2129-2135.

45. Abraham, M. J., Murtola, T., Schulz, R., Páll, S., Smith, J. C., Hess, B., and Lindahl, E. (2015) GROMACS: High performance molecular simulations through multi-level parallelism from laptops to supercomputers, SoftwareX 1-2, 19-25.

46. Cochrane, S. A., Findlay, B., Bakhtiary, A., Acedo, J. Z., Rodriguez-Lopez, E. M., Mercier, P., and Vederas, J. C. (2016) Antimicrobial lipopeptide tridecaptin A1 selectively binds to Gram-negative lipid II, Proc. Natl. Acad. Sci. U. S. A. 113, 1156111566.

47. Johansson, E. M. V., Kadam, R. U., Rispoli, G., Crusz, S. A., Bartels, K.-M., Diggle, S. P., Camara, M., Williams, P., Jaeger, K.-E., Darbre, T., and Reymond, J.-L. (2011) 
Inhibition of Pseudomonas aeruginosa biofilms with a glycopeptide dendrimer containing D-amino acids, Medchemcomm 2, 418-420.

48. Hofmann, A., Sommer, R., Hauck, D., Stifel, J., Gottker-Schnetmann, I., and Titz, A. (2015) Synthesis of mannoheptose derivatives and their evaluation as inhibitors of the lectin LecB from the opportunistic pathogen Pseudomonas aeruginosa, Carbohydr. Res. 412, 34-42.

49. Sommer, R., Hauck, D., Varrot, A., Wagner, S., Audfray, A., Prestel, A., Moller, H. M., Imberty, A., and Titz, A. (2015) Cinnamide Derivatives of d-Mannose as Inhibitors of the Bacterial Virulence Factor LecB from Pseudomonas aeruginosa, ChemistryOpen 4, 756-767.

50. Sommer, R., Wagner, S., Rox, K., Varrot, A., Hauck, D., Wamhoff, E. C., Schreiber, J., Ryckmans, T., Brunner, T., Rademacher, C., Hartmann, R. W., Bronstrup, M., Imberty, A., and Titz, A. (2018) Glycomimetic, Orally Bioavailable LecB Inhibitors Block Biofilm Formation of Pseudomonas aeruginosa, J. Am. Chem. Soc. 140, 25372545.

Graphics for the Table of Contents:

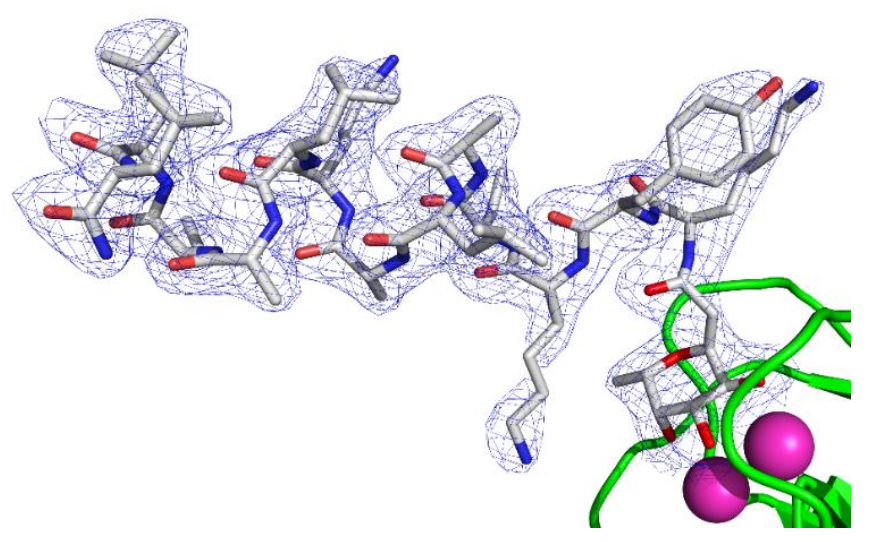

